\title{
Development of a large-scale remote sensing ecological index in arid areas and its application in the Aral Sea Basin
}

\author{
WANG Jie, LIU Dongwei*, MA Jiali, CHENG Yingnan, WANG Lixin \\ School of Ecology and Environment, Inner Mongolia University, Hohhot 010021, China
}

\begin{abstract}
The Aral Sea Basin in Central Asia is an important geographical environment unit in the center of Eurasia. It is of great significance to the ecological protection and sustainable development of Central Asia to carry out dynamic monitoring and effective evaluation of the eco-environmental quality of the Aral Sea Basin. In this study, the arid remote sensing ecological index (ARSEI) for large-scale arid areas was developed, which coupled the information of the greenness index, the salinity index, the humidity index, the heat index, and the land degradation index of arid areas. The ARSEI was used to monitor and evaluate the eco-environmental quality of the Aral Sea Basin from 2000 to 2019. The results show that the greenness index, the humidity index and the land degradation index had a positive impact on the quality of the ecological environment in the Aral Sea Basin, while the salinity index and the heat index exerted a negative impact on the quality of the ecological environment. The eco-environmental quality of the Aral Sea Basin demonstrated a trend of initial improvement, followed by deterioration, and finally further improvement. The spatial variation of these changes was significant. From 2000 to 2019, grassland and wasteland (saline alkali land and sandy land) in the central and western parts of the basin had the worst ecological environment quality. The areas with poor ecological environment quality are mainly distributed in rivers, wetlands, and cultivated land around lakes. During the period from 2000 to 2019, except for the surrounding areas of the Aral Sea, the ecological environment quality in other areas of the Aral Sea Basin has been improved in general. The correlation coefficients between the change in the eco-environmental quality and the heat index and between the change in the eco-environmental quality and the humidity index were -0.593 and 0.524 , respectively. Climate conditions and human activities have led to different combinations of heat and humidity changes in the eco-environmental quality of the Aral Sea Basin. However, human activities had a greater impact. The ARSEI can quantitatively and intuitively reflect the scale and causes of large-scale and long-time period changes of the eco-environmental quality in arid areas; it is very suitable for the study of the eco-environmental quality in arid areas.
\end{abstract}

Keywords: eco-environmental quality; arid remote sensing ecological index; Moderate Resolution Imaging Spectroradiometer (MODIS); landscape changes; remote sensing monitoring; Central Asia

Citation: WANG Jie, LIU Dongwei, MA Jiali, CHENG Yingnan, WANG Lixin. 2021. Development of a large-scale remote sensing ecological index in arid areas and its application in the Aral Sea Basin. Journal of Arid Land, 13(1): 40-55. https://doi.org/10.1007/s40333-021-0052-y

\section{Introduction}

Eco-environmental quality is an important indicator for evaluating regional ecological events and

\footnotetext{
*Corresponding author: LIU Dongwei (E-mail: liudw@imu.edu.cn)

Received 2020-05-13; revised 2020-08-15; accepted 2020-08-24

(C) Xinjiang Institute of Ecology and Geography, Chinese Academy of Sciences, Science Press and Springer-Verlag GmbH Germany, part of Springer Nature 2021
} 
for providing an early warning of environmental events (Chai and Lha, 2018). From the perspective of protecting the eco-environment, the scientific, comprehensive, and accurate assessment of the eco-environmental quality and its changes is crucial to regional development (Wang et al., 2015). It is necessary to evaluate the eco-environment quality of arid areas for the following reasons. First, in recent years, eco-environmental problems in arid areas, such as desertification, soil and grassland degradation, air pollution, and water pollution, have been progressively worsening. Eco-environmental quality assessment in arid areas has become an important research topic (Song et al., 2012). Second, the eco-environment of arid areas is fragile, which makes the areas highly susceptible to natural and human activities and subject to secondary damage. The dynamic monitoring of the eco-environmental quality in arid areas is of great significance for water and soil conservation and ecological degradation prevention (Kang et al., 2012; Jiang et al., 2019).

Evaluations of the eco-environmental quality began in the 1960s and developed rapidly in the 1970s (Chai and Lha, 2018). However, initial assessments of the eco-environment quality mainly focused on specific elements, such as the water environment (Nõges et al., 2007), soil environment (Posthuma and Suter, 2011), and atmospheric environment (Park et al., 2013). Many research methods have been applied to different research objects including the analytic hierarchy process (Ying et al., 2007), the fuzzy weighting method (Wei et al., 2013), and the neural network method (Li and Zhang, 2008). In recent years, with the rapid development of remote sensing methods and technology, the scope and efficiency of the eco-environmental quality assessment have been increased (Fan et al., 2013), and many environmental indices have been developed, such as the National Wildlife Federation environmental quality index in the United States (Dagani, 1990) and the total environmental quality index in Canada. In China, the eco-environmental status index (EI) was first proposed by the former Ministry of Environmental Protection of People's Republic of China (Zhang et al., 2010). In 2015, the former Ministry of Environmental Protection of People's Republic of China revised the index and enriched the information content of the evaluation indicators. In recent years, with the progress of 3S (RS, GIS, and GPS) technology, many 3S-based eco-environmental evaluation indices have been proposed. For example, the comprehensive index uses 11 indicators to evaluate the eco-environmental quality (Baig et al., 2014; Sun et al., 2015), although data for some indicators are more difficult to obtain. The remote sensing ecological index (RSEI) is a comprehensive eco-environmental evaluation index based on natural indicators, but it is more applicable to the county level (Xu et al., 2018; $\mathrm{Hu}$ and $\mathrm{Xu}, 2019$ ). Although the data for the index can be obtained more easily, the applicability of the index to arid areas needs to be further studied because the index is designed for use in urban environments. The eco-environment background value is more comprehensive and systematic in evaluating the eco-environmental quality by adopting remote sensing attributes, meteorological attributes, and natural attributes as evaluation indicators. However, the scales of previous research into monitoring the eco-environmental quality are mostly county-level or township-level, with few larger scale studies. In addition, in terms of the study of the eco-environment quality in arid areas, previous studies adopted evaluation methods applicable to cities, which lack suitable evaluation indicators for the characteristics of arid environments. Therefore, in this study, we corrected this lack of eco-environmental quality evaluation in large-scale arid areas by developing a large-scale eco-environmental quality index suitable for arid areas, which can be used to temporally and spatially study the changes in and distribution of the eco-environment quality in arid areas.

The goals of this study are as follows: (1) to develop an arid remote sensing ecological index (ARSEI) suitable for the assessment of the regional eco-environmental quality in large-scale arid areas; (2) to study the applicability of the ARSEI to the Aral Sea Basin because the Aral Sea is considered to be a typical case of ecosystem collapse, and to analyze the spatial differentiation rules of the eco-environmental quality of the Aral Sea Basin in 2000-2019; and (3) to explore the spatial-temporal variations in the eco-environmental quality of the Aral Sea Basin in order to provide a basis for comprehensive management and scientific development. The ARSEI developed in this study can not only determine real-time and objective changes in the eco-environment quality in arid areas, but also provide a basis for the promulgation of ecological measures and the timely supervision of the implementation progress of ecological engineering, supporting a theory for 
sustainable development in the Aral Sea Basin.

\section{Materials and methods}

\subsection{Study area}

The Aral Sea Basin, between $33^{\circ} \mathrm{N}$ and $52^{\circ} \mathrm{N}$ and between $56^{\circ} \mathrm{E}$ and $78^{\circ} \mathrm{E}$, is located in the center of the Eurasian continent and covers an area of about $1.902 \times 10^{6} \mathrm{~km}^{2}$, of which about $0.821 \times 10^{6}$ $\mathrm{km}^{2}$ is bare land (Fig. 1) (Micklin, 2007). The Aral Sea Basin covers all of Tajikistan and Uzbekistan, the majority of Turkmenistan, three states of Kyrgyz Republic (Osh, Jalalabad, and Naryn), the southern part of Kazakhstan (Kyzylorda and Batysdy Kazakstan regions), and the northern parts of Afghanistan and Iran. The main land cover types in the basin include deserts, wetlands, and grasslands (Fig. 1) (McDermid and Winter, 2017). The climate of the Aral Sea Basin is extremely continental, with extreme desertification, small amounts of irregular precipitation, and large daily temperature differences and seasonal temperature differences. Two main rivers run through the Aral Sea Basin: the Syr Darya River in the north and the Amu Darya River in the south. From 1960 to 1998 , the lake surface shrank by about $60 \%$, and the water volume decreased by about $80 \%$ (Aladin, 2008). Since 2000, as the climate continued to dry up, the water level dropped drastically, the lake area decreased significantly, several species became extinct, salt accumulation decreased, the amount of vegetation reduced, and the eco-environment was severely damaged. The Aral Sea is considered to be a typical case of ecosystem collapse. The ecosystem of the Aral Sea and the delta that flows into the Aral Sea have been almost destroyed completely (Keith et al., 2013). In addition, long-term and large-scale assessments of the eco-environment in the Aral Sea Basin are very scarce, and the spatial differentiation characteristics of the eco-environmental quality of the Aral Sea are rarely studied.

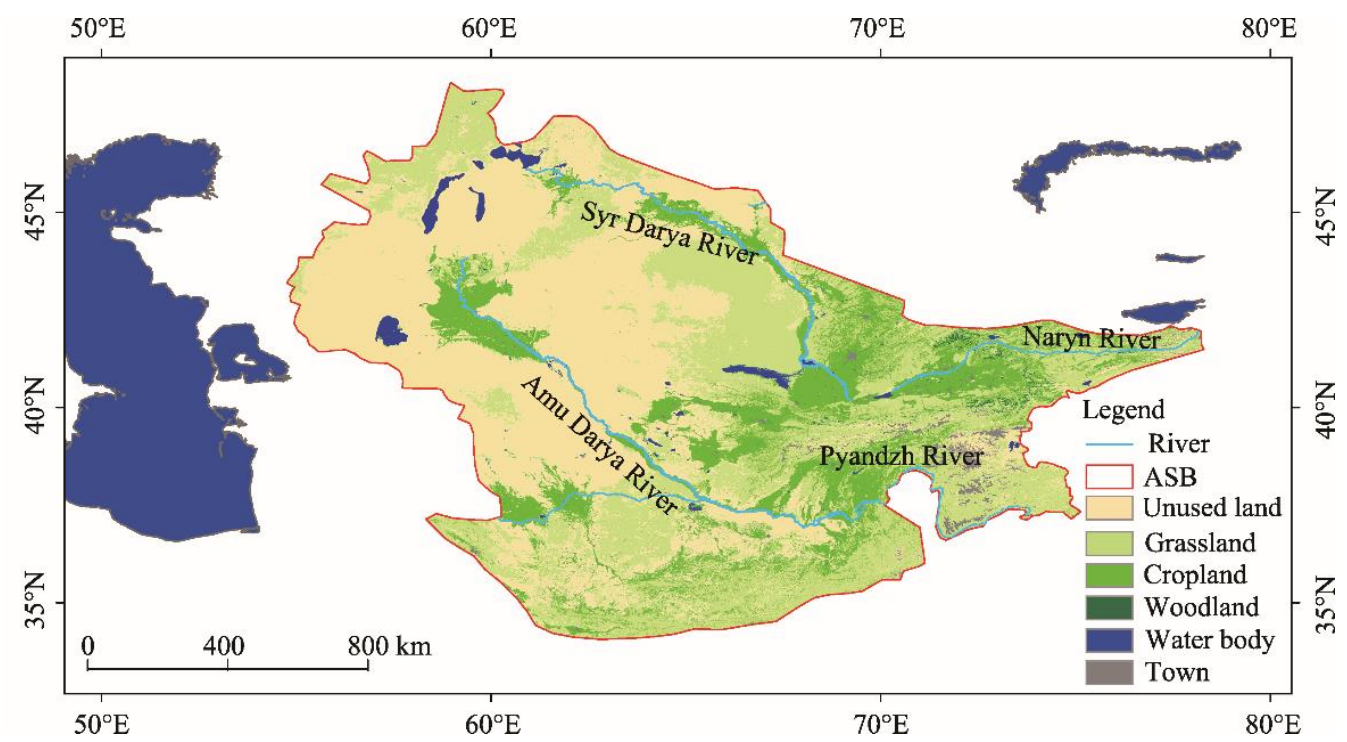

Fig. 1 Overview and land cover types of the study area. ASB, Aral Sea Basin.

\subsection{Data}

In this study, we used the Moderate Resolution Imaging Spectroradiometer (MODIS) series products and the digital elevation model (DEM) data for August 2000-2019 downloaded from the National Aeronautics and Space Administration (NASA) (https://ladsweb.modaps.eosdis.nasa.gov/) (see Table 1 for specific parameters). The MODIS resampling tool of the environment for visualizing images (ENVI) software was used to extract the necessary bands in the MODIS products and to transform the projection coordinates into Universal Transverse Mercator coordinates. We used the maximum synthesis tool in the ENVI software to synthesize data with a 
time resolution of $8 \mathrm{~d}$ into monthly data. The slope analysis tool in ArcGIS was used to analyze the slope of the DEM to obtain the slope data.

The climate and social data used in this study included the average precipitation in July 20002015, the average temperature in July 2000-2015, the average evapotranspiration in July 20002015 (Deng et al., 2017; Xu, 2019), and the irrigation water demand for winter wheat and cotton in 2005-2015 (Peng et al., 2019). The above data were obtained from the National Tibetan Plateau Data Center (https://data.tpdc.ac.cn/zh-hans/). Among them, the irrigation water demand for crops was used as the index of man-made influences, and the temperature, precipitation, and evapotranspiration were used as indices of climate impact.

The hydrological analysis of the DEM was carried out using ArcGIS, and the boundary of the Aral Sea Basin was obtained. Finally, according to the boundary of the Aral Sea Basin, we clipped the research data to obtain remote sensing images and natural and human data for the Aral Sea Basin.

Table 1 Product names, product functions, and temporal and spatial resolutions of the Moderate Resolution Imaging Spectroradiometer (MODIS) data

\begin{tabular}{cccc}
\hline Product name & Product function & Temporal resolution & Spatial resolution \\
\hline MOD09A1 & Surface reflectance & $8 \mathrm{~d}$ & $500 \mathrm{~m}$ \\
MOD11A2 & Surface temperature & $8 \mathrm{~d}$ & $1000 \mathrm{~m}$ \\
MOD13A3 & Vegetation index & Monthly & $1000 \mathrm{~m}$ \\
MCD12Q1 & Land cover type & Yearly & $500 \mathrm{~m}$ \\
ASTER-GDEM & Digital elevation & & $30 \mathrm{~m}$ \\
\hline
\end{tabular}

\subsection{Selection of the arid remote-sensing ecological index (ARSEI) evaluation indicators}

Arid areas in Eurasia are mainly characterized by a continental climate, which is hot and dry, with little precipitation, large amounts of evaporation, and serious water shortages (Breyfogle, 2018). The main geomorphic types in the arid area are deserts, grasslands, and wasteland. The desert area is large, the oasis area is small, the area covered by natural vegetation is small, and the degree of land salinization is high (Breyfogle, 2018). The eco-environment of the Aral Sea Basin assessed in this study mainly has the following outstanding characteristics: first, rainfall is scarce and the land surface is dry; second, the temperature changes violently; third, the area of saline alkali land is increasing; fourth, the desert area is expanding, the oasis area is shrinking, and the natural vegetation area is decreasing; and fifth, the utilization of water resources is unreasonable and the amount of human disturbance is significant (Zhou et al., 2006). According to the above five characteristics, combined with the research purpose of large-scale remote sensing environmental monitoring, we selected remote sensing monitoring indicators that reflect the different ecological environmental changes and can be retrieved from low and medium resolution images to create the ARSEI for the real-time and rapid monitoring of the eco-environmental quality changes. The ARSEI established in this study included the greenness index, the humidity index, the salinity index, the heat index, and the land degradation index. The descriptions of each index, the reasons for their selection, and their calculation methods were discussed below.

\subsubsection{Greenness index}

The greenness indicates the growth state and vegetation coverage of the surface vegetation. In arid areas, the vegetation determines the composition and structure of the ecosystem. It also ensures the stability of ecosystems in arid areas and protects human populations from the effects of desertification (Mamat et al., 2018). In addition, vegetation coverage is an important information index of land cover changes. The impact of both natural factors (such as climate change) and human factors (human activities) on the eco-environment quality is directly reflected by changes in the vegetation type and vegetation coverage (Wang et al., 2010). In the Aral Sea Basin, the area of natural vegetation and oasis has decreased, so the coverage and growth of vegetation in the basin can be monitored using the greenness index. The vegetation fractional coverage (VFC) (Zhao et al., 
2018) is the greenness index used in this study. The VFC is defined as the proportion of vegetation per unit area, and it is usually calculated using the normalized difference vegetation index (NDVI) (Shobairi et al., 2018), i.e., Equations 1 and 2.

$$
\begin{gathered}
\mathrm{NDVI}=\frac{\mathrm{R}_{\mathrm{NIR}}-\mathrm{R}_{\mathrm{R}}}{\mathrm{R}_{\mathrm{NIR}}+\mathrm{R}_{\mathrm{R}}}, \\
\mathrm{VFC}=\frac{\mathrm{NDVI}-\mathrm{NDVI}_{\text {soil }}}{\mathrm{NDVI}_{\mathrm{veg}}-\mathrm{NDVI}_{\text {soil }}},
\end{gathered}
$$

where NDVI is the normalized difference vegetation index (dimensionless, from -1 to 1 ); $R_{\text {NIR }}$ is the reflection in the near infrared with wavelengths of $841-876 \mathrm{~nm}$ (dimensionless, from 0 to 1 ), which was obtained from the $2^{\text {nd }}$ band of MOD09A1; $R_{R}$ is the reflection in the red with wavelength of $620-670 \mathrm{~nm}$ (dimensionless, from 0 to 1 ), which was obtained from the $1^{\text {st }}$ band of MOD09A1; VFC is the vegetation fractional coverage; NDVI $_{\text {soil }}$ is the NDVI value of the area of completely bare soil or the area without vegetation cover; and $\mathrm{NDVI}_{\mathrm{veg}}$ is the NDVI value of the area completely covered by vegetation.

\subsubsection{Humidity index}

The humidity represents the water content of the ground surface, including the water content of the vegetation, soil, and surface water, and thus, it plays an important role in the evaluation of the eco-environmental quality in arid areas (Zheng et al., 2015). Water resources are scarce and indispensable in arid and semi-arid areas. The eco-environmental quality in arid areas depends on the availability of water resources (Mo et al., 2019). In addition, surface water is an important part of the land water cycle, which affects the material exchange with and energy balance of the surface. In arid areas, there is less precipitation and but strong evapotranspiration. Soil moisture is one of the most important ecological factors (Mladenova et al., 2014). Furthermore, we can obtain the surface drought dynamics and the distribution of water resources in arid areas in real time, which is of great significance for drought resistance and ecological environmental protection (Wang et al., 2019). The humidity index used in this study is the land surface water index (LSWI) (Dong et al., 2014), which is calculated as shown in Equation 3.

$$
\mathrm{LSWI}=\frac{\mathrm{R}_{\mathrm{NIR}}-\mathrm{R}_{\mathrm{SWIR}}}{\mathrm{R}_{\mathrm{NIR}}+\mathrm{R}_{\mathrm{SWIR}}},
$$

where LSWI is the land surface water index; $\mathrm{R}_{\mathrm{NIR}}$ is the reflection in the near infrared with wavelengths of 841-876 $\mathrm{nm}$ (dimensionless, from 0 to 1 ), which was obtained from the $2^{\text {nd }}$ band of MOD09A1; and RswIR is the reflection in the shortwave infrared with wavelengths of 2105-2155 $\mathrm{nm}$ (dimensionless, from 0 to 1 ), which was obtained from the $7^{\text {th }}$ band of MOD09A1.

\subsubsection{Salinity index}

Soil salinization refers to the process of land quality degradation caused by soil salinity increasing resulted from the integrated impact of various natural factors, such as the specific climate, geological processes, soil texture, and improper irrigation. Salinization seriously impedes agricultural development in arid areas. It is also an important factor affecting the ecological stability of oases (Nishikawa and Yasuda, 2011). When the salt accumulation in the soil reaches a certain critical value, it inhibits the ability of crop roots to absorb water and nutrients, and can corrode plant roots, damaging the normal growth and development of crops. Soil salinization not only seriously damages the production potential of the soil, but also causes significant losses in agricultural production. In addition, the accumulation of salt changes the soil environment to promote the growth of halophyte plants, eventually leading to the deterioration of the eco-environment (Bennett, 2003). The salinity index is used to quantify and evaluate the impact of salinization on the eco-environmental quality in arid areas. In this study, the surface salinity index (SI-T) (Khan et al., 2005; Allbed et al., 2014; Guo et al., 2020a) was used as the salinity index. It is calculated as shown in Equation 4.

$$
\mathrm{SI}-\mathrm{T}=100 \times\left(\mathrm{R}_{\mathrm{R}} / \mathrm{R}_{\mathrm{NIR}}\right)
$$


where SI-T is the surface salinity index; $R_{R}$ is the reflection in the red with wavelengths of 620$670 \mathrm{~nm}$ (dimensionless, from 0 to 1 ), which was obtained from the $1^{\text {st }}$ band of MOD09A1; and $\mathrm{R}_{\text {NIR }}$ is the reflection in the near infrared with wavelengths of $841-876 \mathrm{~nm}$ (dimensionless, from 0 to 1 ), which was obtained from the $2^{\text {nd }}$ band of MOD09A1.

\subsubsection{Heat index}

The heat index reflects the surface temperature, making it a particularly important parameter for the assessment of the eco-environmental quality in arid areas. Surface temperature is also an important indicator of land degradation, salinization, desertification, erosion, and climate change. In terms of the eco-environmental quality monitoring, surface temperature can reflect water pollution in real time, and can be used for drought monitoring. Since the surface of the Aral Sea Basin is dry and the temperature changes violently, the heat index was selected to obtain the temporal and spatial variations in the drought degree of the study area. In this study, the land surface temperature (LST) (Langer et al., 2010) was used as the heat index, as shown in Equation 5.

$$
\text { Heat=LST, }
$$

where Heat is the heat index; and LST is the land surface temperature in $\mathrm{K}$, which was obtained from the $0.02 \times \mathrm{NG}\left(0.02\right.$ is the scale factor, and NG is the $1^{\text {st }}$ band of MOD11A2).

\subsubsection{Land degradation index}

Land degradation refers to the decline in land quality and productivity under the influence of adverse natural factors and unreasonable use of the land by humans (Smiraglia et al., 2015). The unique climate conditions in arid and semi-arid areas have a greater impact on the land degradation process. Significant warming and aridity aggravate water shortages, change the ecological hydrological processes, and affect and degrade the eco-environmental quality in arid areas (Alves et al., 2015). In arid areas, the main types of land degradation are land desertification and soil erosion. Land salinization and desertification are serious problems in the Aral Sea Basin. Therefore, the land degradation index was selected as the component index of the ARSEI to obtain the general land degradation situation in the study area to enable real-time ecological protection.

The land degradation index is usually expressed by the land degradation intensity (Guo et al., 2020b). The data for the land degradation intensity are partially missing due to incomplete data acquisition in the Aral Sea Basin. Therefore, in this study, we used an indirect method to extract the land degradation intensity information. Combined with the actual situation of the arid area, we applied the expert decision tree classification method (Jiang et al., 2010; Wang, 2013) to determine the classification index of the land degradation intensity in arid areas according to the vegetation coverage, land cover, and slope from the ENVI, as shown in Equation 6 and Table 2. There are six grades of soil erosion: slight, mild, moderate, intense, extreme, and violent erosion. Slight soil erosion indicates that the ecosystem is not affected and basically does not need to be restored. Mild soil erosion implies that the ecosystem is slightly affected and can be easily recovered if reasonable measures are taken. Moderate soil erosion means that the ecosystem is partially damaged, and strong measures are needed to restore it. Intense soil erosion indicates the basic loss of ecosystem functions, which can be restored only by taking strong biological and engineering measures. Extreme soil erosion indicates the complete loss of ecosystem functions, which are difficult to be restored. Violent soil erosion implies that the ecosystem functions cannot be restored. The land degradation intensity of water areas, towns, and residential areas is slight. The analytic hierarchy process method (AHP) (Rastorgueff et al., 2015; Nyimbili et al., 2018) was used to transform the land degradation intensity into the land degradation index using the YAAHP software (an analytic hierarchy process software produced by Shanxi Yuan Decision Software Technology Co. Ltd., China), as shown in Equation 7 and Table 3 (Guo et al., 2020b).

$$
\begin{gathered}
\text { LDI=Class (VFC, LC, SLOPE), } \\
\text { LD }=\text { AHP (LDI), }
\end{gathered}
$$

where LDI is the land degradation intensity, including six grades of soil erosion, namely, slight, mild, moderate, intense, extreme, and violent; Class stands for expert classifier, using ENVI; VFC is the vegetation fractional coverage; $\mathrm{LC}$ is the land cover, which was obtained from the $1^{\text {st }}$ band of 
MCD12Q1; SLOPE is the ground slope $\left(^{\circ}\right)$; LD is the land degradation index (from 0 to 1 ); and AHP is the analytic hierarchy process.

Table 2 Land degradation intensity of different land use types with different levels of coverage and slope

\begin{tabular}{cccccccc}
\hline \multirow{2}{*}{$\begin{array}{c}\text { Land use } \\
\text { type }\end{array}$} & $\begin{array}{c}\text { Vegetation } \\
\text { coverage }\end{array}$ & \multicolumn{5}{c}{ Land degradation intensity } \\
\cline { 3 - 8 } & $>75 \%$ & Slope $<5^{\circ}$ & $5^{\circ} \leq$ Slope $<8^{\circ}$ & $8^{\circ} \leq$ Slope $<15^{\circ}$ & $15^{\circ} \leq$ Slope $<25^{\circ}$ & $25^{\circ} \leq$ Slope $<35^{\circ}$ & Slope $\geq 35^{\circ}$ \\
\hline \multirow{2}{*}{$\begin{array}{c}\text { Forest and } \\
\text { grassland }\end{array}$} & $60 \%-75 \%$ & Slight & Mlight & Slight & Slight & Slight & Slight \\
& $30 \%-60 \%$ & Slight & Mild & Mild & Mild & Moderate & Moderate \\
& $<30 \%$ & Slight & Mild & Moderate & Moderate & Intense & Extreme \\
Farmland & - & Slight & Moderate & Moderate & Intense & Extreme & Violent \\
\hline
\end{tabular}

Table 3 Land degradation index values of different land degradation intensities

\begin{tabular}{ccccccc}
\hline \multirow{2}{*}{$\begin{array}{c}\text { Land degradation } \\
\text { index }\end{array}$} & Slight & Mild & Moderate & Intense & Extreme & Violent \\
\cline { 2 - 7 } & 0.0513 & 0.0412 & 0.1302 & 0.2650 & 0.5123 & 0.6342 \\
\hline Value & 0.0532 &
\end{tabular}

\subsection{ARSEI evaluation methods}

\subsubsection{ARSEI construction}

The ARSEI was calculated using principal component analysis (PCA) (Hu and $\mathrm{Xu}, 2018$ ) instead of the traditional weighting method. In order to eliminate the influence of different index dimensions, we standardized the above-mentioned five indices. Then, the PCA was used to obtain the weight, which in turn generated the $\mathrm{ARSEI}_{0}$ value (Eq. 8). We standardized the $\mathrm{ARSEI}_{0}$ (Eq. 9) to obtain the final ARSEI to compare and analyze the ARSEI in different time periods.

$$
\operatorname{ARSEI}_{0}=1-\mathrm{PC} 1(\mathrm{G}, \mathrm{H}, \mathrm{S}, \mathrm{He}, \mathrm{LD}) \text {, }
$$

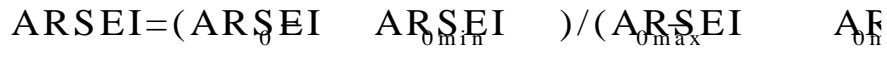

where $\mathrm{ARSEI}_{0}$ is the initial value of the arid remote sensing ecological index (from -1 to 1 ); $\mathrm{PC} 1$ is the first principal component in the PCA; $\mathrm{G}$ is the greenness index; $\mathrm{H}$ is the humidity index; $\mathrm{S}$ is the salinity index; He is the heat index; LD is the land degradation index; ARSEI is the final value of the arid remote sensing ecological index (from 0 to 1 ); $\mathrm{ARSEI}_{0 \min }$ is the minimum value of the $\mathrm{ARSEI}_{0}$; and $\mathrm{ARSEI}_{0 \max }$ is the maximum value of the $\mathrm{ARSEI}_{0}$.

\subsubsection{ARSEI analysis methods}

In the Technical Criterion for Ecosystem Status Evaluation issued by the former Ministry of Environmental Protection of People's Republic of China (Zheng et al., 2018), the ecological environment was divided into five grades with a $20 \%$ interval: best, good, general, poor, and worst (Zheng et al., 2018). Xu (2013) established the RSEI ecological environment quality grading evaluation system according to this standard. According to this classification, we classified the ARSEI into five grades at intervals of 0.2 , representing five levels of eco-environmental quality, i.e., $0.0-0.2$ is the worst, $0.2-0.4$ is poor, $0.4-0.6$ is general, $0.6-0.8$ is good, and $0.8-1.0$ is the best, in order to visualize and quantify the analysis of the regional eco-environmental quality (Shan et al., 2019; Ning et al., 2020; Zhu et al., 2020).

According to the Technical Criterion for Ecosystem Status Evaluation issued by the former Chinese Ministry of Environmental Protection (Zheng et al., 2018), there are seven levels of the intensity of the eco-environmental change, namely, $|\Delta \mathrm{EI}|<1 \%$ (EI represents the eco-environmental status index) indicates no obvious change, $1 \% \leq|\Delta \mathrm{EI}|<3 \%$ indicates a slight change, $3 \% \leq|\Delta \mathrm{EI}| \leq 8 \%$ indicates an obvious change, and $|\Delta \mathrm{EI}|>8 \%$ indicates a significant change. In this study, we adjusted the range of the seven grades in order to highlight the dynamic change intensity of the ecological environment in arid areas according to the characteristics of the drastic change in the 
natural factors in arid areas. The annual difference in the ARSEI (Eq. 10) can be divided into seven grades: -1.00 to -0.10 , significantly worse (D3); -0.10 to -0.05 , obviously worse (D2); -0.05 to 0.02 , slightly worse (D1); -0.02 to 0.02 , no change; 0.02 to 0.05 , slightly better (U1); 0.05 to 0.10 , obviously better (U2); and 0.10 to 1.00 , significantly better (U3).

$$
\mathrm{D} \text { value }=\mathrm{ARSEI}_{\mathrm{a}}-\mathrm{ARSEI}_{\mathrm{b}} \text {, }
$$

where D value is the annual difference in the ARSEI; ARSEI ${ }_{a}$ is the ARSEI value of year a; and $\mathrm{ARSEI}_{\mathrm{b}}$ is the ARSEI value of year $b$.

Based on the correlation between the variance of the ARSEI and the variance of the other indices, we can accurately identify and quantitatively measure the main influencing factors causing the changes in the ARSEI. In this study, the correlation index was calculated using the Pearson correlation coefficient (Eq. 11).

$$
r=\frac{\sum(X-\bar{X})(Y-\bar{Y})}{\sqrt{\sum(X-\bar{X})^{2} \sum(Y-\bar{Y})^{2}}},
$$

where $r$ is the Pearson correlation coefficient; and $X$ and $Y$ are variables.

\section{Results}

\subsection{Analysis of the eco-environmental quality assessment model for the Aral Sea Basin}

Table 4 shows the index weights of the ARSEI results for the Aral Sea Basin in 2000, 2005, 2010, 2015, and 2019. The cumulative contribution rate of the first principal component in the PCA from 2000 to 2019 was greater than $80 \%$. In other words, of the five indices, the first principal component included the most information. In the first principal component, the positive and negative contributions of the five indices were obvious, which explained the correlation between the five indices and the eco-environmental quality. The weights of the greenness index, the humidity index, and the land degradation index were negative. That is to say, these indices were positively correlated with the ARSEI, and they had a positive impact on the eco-environmental quality. The weights of the salinity index and the heat index were positive because these indices were negatively correlated with the ARSEI and they had a negative impact on the eco-environmental quality. The contribution weights of the greenness index and the salinity index were relatively small, with most being $0.200-0.300$. The weight of the humidity index was about 0.350 , that of the land degradation index was greater than 0.500 , and that of the heat index was greater than 0.600 . Therefore, the land degradation index and the heat index are the two most essential factors in building the ARSEI.

Table 4 Contribution weights of the five indices in the arid remote-sensing ecological index (ARSEI) in 2000, $2005,2010,2015$, and 2019

\begin{tabular}{cccccccc}
\hline Year & PC & G & H & S & He & LD & $\begin{array}{c}\text { Accumulated } \\
\text { contribution rate } \\
(\%)\end{array}$ \\
\hline 2000 & PC1 & -0.232 & -0.332 & 0.232 & 0.623 & -0.669 & 80.879 \\
2005 & PC1 & -0.284 & -0.323 & 0.226 & 0.733 & -0.527 & 82.818 \\
2010 & PC1 & -0.325 & -0.365 & 0.372 & 0.696 & -0.526 & 83.783 \\
2015 & PC1 & -0.277 & -0.321 & 0.275 & 0.667 & -0.613 & 82.418 \\
2019 & PC1 & -0.389 & -0.382 & 0.366 & 0.620 & -0.563 & 82.151 \\
\hline
\end{tabular}

Note: PC, a component of the principal component analysis (PCA); PC1, the first principal component in the PCA; G, the greenness index; $\mathrm{H}$, the humidity index; $\mathrm{S}$, the salinity index; He, the heat index; $\mathrm{LD}$, the land degradation index.

\subsection{Time difference analysis of the eco-environmental quality in the Aral Sea Basin}

Table 5 shows the areas and percentages of five grades of the eco-environmental quality in the Aral Sea Basin in 2000, 2005, 2010, 2015, and 2019, using the ARSEI. According to Table 5, the eco-environmental quality within more than $60 \%$ of the area of the Aral Sea Basin fell into the 
worst level from 2000 to 2019. During the period 2000-2005, the eco-environmental quality in the Aral Sea Basin improved because the area with the worst category decreased compared with that in 2000 , and the areas of the other levels increased. The eco-environmental quality of the Aral Sea Basin was stable from 2005 to 2010, decreased from 2010 to 2015, and improved from 2015 to 2019. Overall, during the period 2000-2019, the eco-environment quality in the Aral Sea Basin initially improved, then deteriorated, and finally improved again.

Table 5 Areas and percentages of the different eco-environmental quality classifications in the Aral Sea Basin in 2000, 2005, 2010, 2015, and 2019 determined using the ARSEI

\begin{tabular}{|c|c|c|c|c|c|c|c|c|c|c|}
\hline \multirow[b]{2}{*}{ Level } & \multicolumn{2}{|c|}{2000} & \multicolumn{2}{|c|}{2005} & \multicolumn{2}{|c|}{2010} & \multicolumn{2}{|c|}{2015} & \multicolumn{2}{|c|}{2019} \\
\hline & $\begin{array}{c}\text { Area } \\
\left(\times 10^{4} \mathrm{~km}^{2}\right)\end{array}$ & $\mathrm{P}(\%)$ & $\begin{array}{c}\text { Area } \\
\left(\times 10^{4} \mathrm{~km}^{2}\right)\end{array}$ & $\mathrm{P}(\%)$ & $\begin{array}{c}\text { Area } \\
\left(\times 10^{4} \mathrm{~km}^{2}\right)\end{array}$ & $\mathrm{P}(\%)$ & $\begin{array}{c}\text { Area } \\
\left(\times 10^{4} \mathrm{~km}^{2}\right)\end{array}$ & $\mathrm{P}(\%)$ & $\begin{array}{c}\text { Area } \\
\left(\times 10^{4} \mathrm{~km}^{2}\right)\end{array}$ & $\mathrm{P}(\%)$ \\
\hline Worst & 135.114 & 70.797 & 125.376 & 65.694 & 127.723 & 66.924 & 132.463 & 69.408 & 123.783 & 64.860 \\
\hline Poor & 39.128 & 20.502 & 42.916 & 22.487 & 41.547 & 21.770 & 42.597 & 22.320 & 43.177 & 22.624 \\
\hline General & 15.529 & 8.137 & 20.318 & 10.646 & 19.965 & 10.461 & 14.728 & 7.717 & 22.516 & 11.798 \\
\hline Good & 1.036 & 0.543 & 2.181 & 1.143 & 1.565 & 0.820 & 1.010 & 0.529 & 1.326 & 0.695 \\
\hline Best & 0.041 & 0.022 & 0.057 & 0.030 & 0.048 & 0.025 & 0.050 & 0.026 & 0.046 & 0.024 \\
\hline Total & 190.848 & 100.001 & 190.848 & 100.000 & 190.848 & 100.000 & 190.848 & 100.000 & 190.848 & 100.001 \\
\hline
\end{tabular}

Note: $\mathrm{P}$ is the percentage of the total area occupied by a certain level.

Figure 2 shows the percentages of the different grades of the eco-environmental quality change in the Aral Sea Basin in 2000-2005, 2005-2010, 2010-2015, 2015-2019, and 2000-2019 determined using the ARSEI variance.

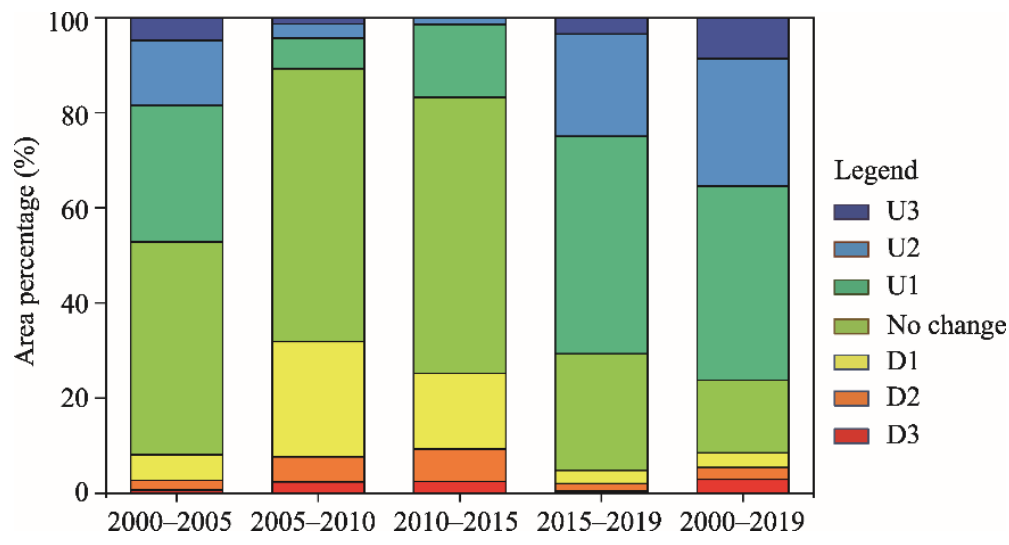

Fig. 2 Area percentages of the different grades of the eco-environmental quality change in the Aral Sea Basin determined using the arid remote sensing ecological index (ARSEI) variance in 2000-2005, 2005-2010, 20102015, 2015-2019, and 2000-2019. U3, significantly better; U2, obviously better; U1, slightly better; D1, slightly worse; D2, obviously worse; D3, significantly worse.

From 2000 to 2005, the eco-environmental quality exhibited no change in about $44.726 \%$ of the Aral Sea Basin (i.e., the largest proportion), followed by slightly better, which accounted for $28.693 \%$. Therefore, although there was no obvious change of the eco-environmental quality between 2000 and 2005, a slight improvement trend existed. From 2005 to 2010, the percentage of the area with no change in the eco-environmental quality increased to $57.391 \%$, the percentage of the area with a slightly worse eco-environmental quality was much larger than that in 2000-2005, and the percentages of the areas with slightly better and obviously better eco-environmental quality significantly decreased. Therefore, although the overall performance of the eco-environmental quality did not change from 2005 to 2010, there was a trend of deterioration. Similarly, the overall performance of the eco-environmental quality from 2010 to 2015 exhibited no obvious change, but it showed signs of decline. From 2015 to 2019, the eco-environmental quality of the Aral Sea Basin improved significantly, in which the largest proportion $(45.786 \%)$ had a slightly better quality. 
Moreover, the proportion of the variation in the deterioration decreased significantly, and the proportion of improvement increased dramatically. In general, from 2000 to 2019, the eco-environmental quality in $40.880 \%$ of the Aral Sea Basin was slightly better. Therefore, the eco-environmental quality in the Aral Sea Basin has been generally improving with some fluctuations during the period 2000-2019.

\subsection{Spatial difference analysis of the eco-environmental quality in the Aral Sea Basin}

Figure 3 shows the classification distribution of the eco-environmental quality in the Aral Sea Basin in 2000, 2005, 2010, and 2019 determined using the ARSEI. Combined with the land cover map of the Aral Sea Basin (Fig. 1), it can be seen that there were few areas with good and best eco-environmental quality, and these areas were scattered in the eastern mountain areas. The general level areas were mainly distributed in the eastern mountain areas as well. There were a small number of wetlands around lakes and rivers such as the Aral Sea, the Syr Darya River, and the Amu Darya River. The areas with poor level were mainly distributed in the river alluvial plain and cultivated land on the river bank, and the areas with the worst level were widely distributed in the central and western parts of the Aral Sea Basin, which included grasslands, saline alkaline lands, and wastelands. In addition, the eco-environmental quality in most of the Aral Sea Basin was of the worst level, followed by the poor grade and the general level.

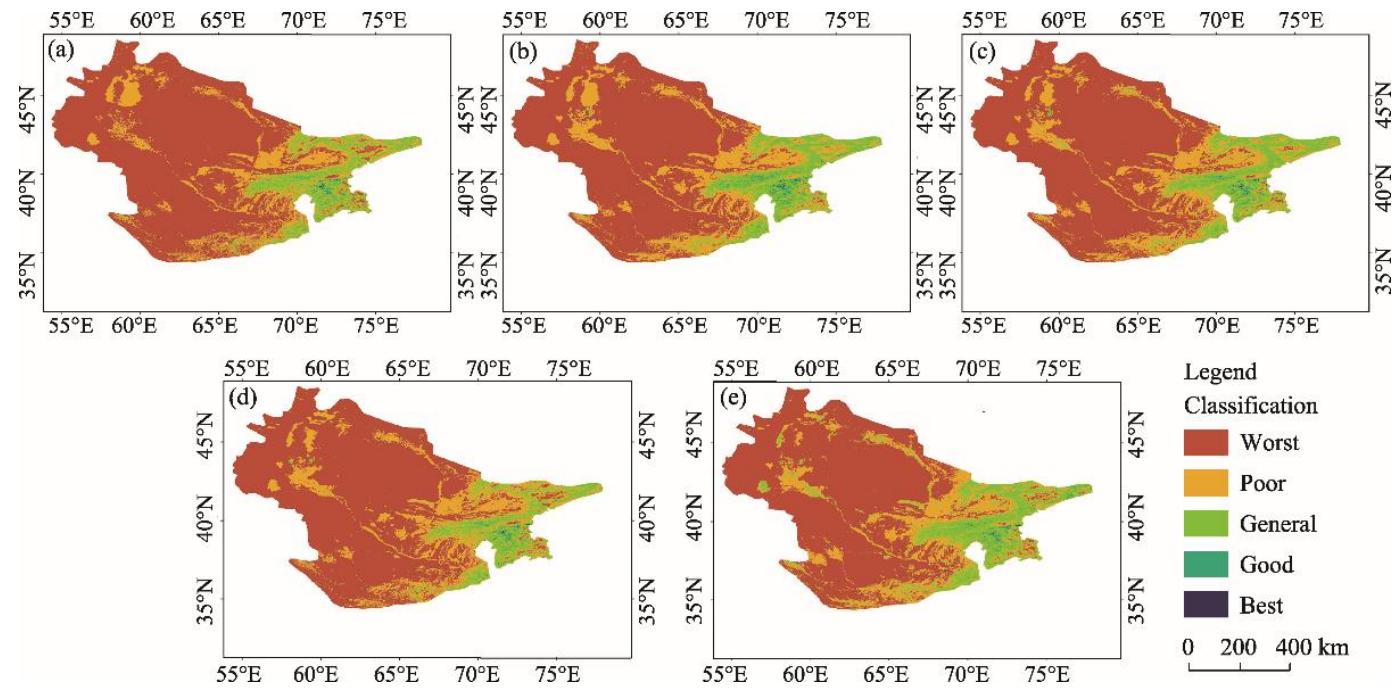

Fig. 3 Eco-environmental quality classification of the Aral Sea Basin obtained using the ARSEI in 2000 (a), 2005 (b), 2010 (c), 2015 (d), and 2019 (e)

\subsection{Reason for the temporal variation of the eco-environment quality in the Aral Sea Basin}

In order to determine the reason for the changes of the eco-environment quality in the Aral Sea Basin, we calculated the correlation among the differences in the five indices, the difference in the average temperature, the difference in the average precipitation, the difference in the average evapotranspiration, the difference in the irrigation water demand for winter wheat and cotton, and the difference in the ARSEI from 2000 to 2019 (see Table 6).

The correlation between the variance of the ARSEI and the variance of the heat index was the highest (mean value of -0.593 ), followed by that of the humidity index (mean value of 0.524 ). The average correlation in 2005-2015 between the change in the ARSEI and the irrigation water demand for cotton and winter wheat was higher than those of the climate factors (temperature, precipitation, and evapotranspiration). Therefore, the change in the eco-environment quality in the Aral Sea Basin was influenced by human activities more than by natural factors. Thus, the main reason for the change in the eco-environmental quality in the Aral Sea Basin from 2000 to 2019 was the annual variance of the heat index, followed by the annual variance of the humidity index. In addition, the correlations between the variance of the ARSEI and the variances of the greenness 
index and the salinity index both increased year by year. Thus, the influence of the greenness index and the salinity index on the change in the eco-environmental quality was also increasing year by year.

Table 6 Correlation coefficients between the variance of the eco-environmental quality and the indices in the Aral Sea Basin in 2000-2005, 2005-2010, 2010-2015, 2015-2019, and 2000-2019 based on Pearson correlation analysis

\begin{tabular}{cccccc}
\hline \multirow{2}{*}{ Index } & \multicolumn{5}{c}{ Variance of the eco-environmental quality } \\
\cline { 2 - 6 } & $2000-2005$ & $2005-2010$ & $2010-2015$ & $2015-2019$ & $2000-2019$ \\
\hline G & 0.299 & 0.262 & 0.495 & 0.442 & 0.257 \\
H & 0.444 & 0.415 & 0.449 & 0.405 & 0.524 \\
He & -0.722 & -0.517 & -0.774 & -0.682 & -0.593 \\
S & -0.300 & -0.263 & -0.496 & -0.443 & -0.258 \\
LD & 0.179 & 0.137 & 0.068 & 0.133 & 0.191 \\
PRE & 0.500 & 0.131 & 0.186 & - & 0.272 \\
TEM & -0.485 & -0.527 & -0.405 & - & -0.472 \\
EVA & -0.173 & -0.099 & -0.417 & - & -0.230 \\
IWD_CON & - & -0.476 & -0.534 & - & -0.505 \\
IWD_WIN & - & -0.487 & -0.520 & - & -0.504 \\
\hline
\end{tabular}

Note: G, the greenness index; H, the humidity index; He is the heat index; S, the salinity index; LD, the land degradation index; PRE, precipitation; TEM, temperature; EVA, evapotranspiration; IWD_CON, the irrigation water demand for cotton; IWD_WIN, the water demand for winter wheat; -, no data available.

\subsection{Spatial change intensity analysis of the eco-environmental quality in the Aral Sea Basin}

The change in the intensity of the regional eco-environmental quality in the Aral Sea Basin from 2000 to 2019 is shown in Figure 4. Apparently, the spatial variation intensity of the eco-environmental quality in the Aral Sea Basin was significant. From 2000 to 2019, the regions with the largest spatial intensity variability in the eco-environmental quality were located around the Aral Sea, on the alluvial plains, and in the irrigated farmland in the lower reaches of the Syr Darya and Amu Darya rivers. Among them, the eco-environmental quality around the Aral Sea was significantly became worse, while the alluvial plain and irrigated farmland areas in the lower reaches of the Syr Darya River and the Amu Darya River became significantly better. The areas with a strong spatial intensity variation in the eco-environmental quality were distributed in the mixed forest and sparse vegetation areas. The eco-environmental quality of the mixed forest improved obviously from 2000 to 2019, while that of the sparse vegetation became obviously worse. The region with a slight spatial intensity variation in the eco-environmental quality was located on the bare land in the central and western parts of the basin, and the eco-environmental quality became slightly better from 2000 to 2019. There was no change in the quality of the eco-environment in the area where the vegetation cover type was shrubs. The spatial variation intensity of the eco-environmental quality in the upper reaches of the Syr Darya and Amu Darya rivers was complex, but it exhibited a trend of deterioration.

\section{Discussion}

In this study, we developed an eco-environment index for determining the eco-environment quality of arid areas, which are divided by the rules of natural zoning, rather than administrative units. Previous eco-environmental indices, such as the EI, were not pertinent to arid areas, because they ignored important elements during evaluating process. The RSEI was established for the urban environment, such as natural areas and arid areas, with a wide research area and a small urban area. Therefore, there are certain defects in its application in arid areas. In this study, based on the RSEI, we established the ARSEI by removing the surface dryness index (the building index and the 


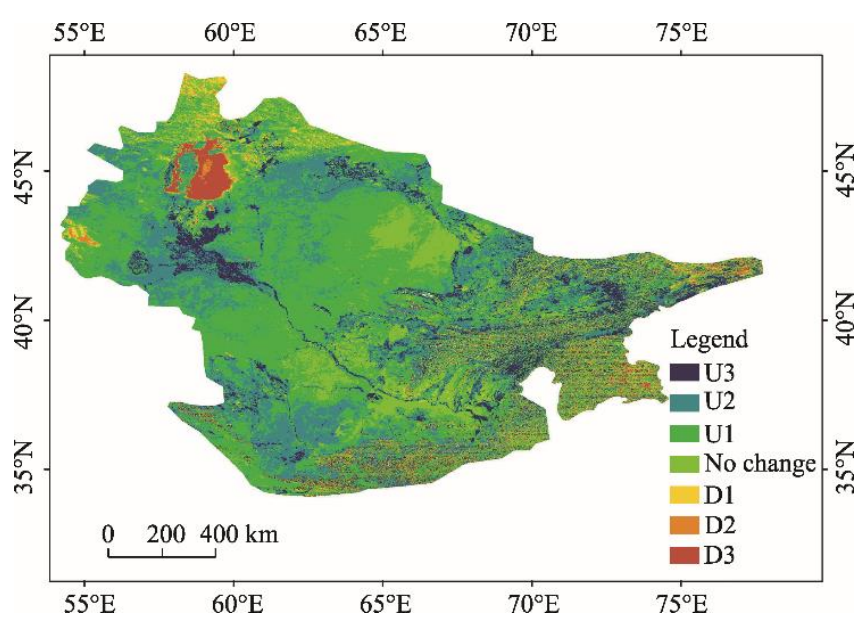

Fig. 4 Changes in the intensity of the regional eco-environmental quality in the Aral Sea Basin determined using the ARSEI in 2000-2019. U3, significantly better; U2, obviously better; U1, slightly better; D1, slightly worse; D2, obviously worse; D3, significantly worse.

surface bare soil index), which represents the urban environment, from the RSEI, and adding the salinity index and the land degradation index to characterize the environment of arid areas. The index has achieved good results in its application to the Aral Sea Basin. The application of this index to other arid areas requires follow-up analysis.

Although it is difficult to verify the accuracy of the results of an eco-environmental quality assessment with specific data, we can effectively verify it using the relevant conclusions in the statistical yearbook and literature. The quality of the regional eco-environment can be determined by the ecological carrying capacity and the social and economic conditions, so the ecological carrying capacity also indirectly reflects the quality of the eco-environment. Wu et al. (2020) evaluated and analyzed the ecological carrying capacity of the Aral Sea Basin from 2000 to 2018 , and found that the ecological carrying capacity of the Aral Sea Basin was mainly medium and poor, and that of the upstream area was better than that of the downstream area, which is consistent with our assessment of the eco-environmental quality. They also revealed that the ecological carrying capacity of the Aral Sea Basin increased from 2001 to 2018, which agrees with our assessment that the eco-environmental quality of the Aral Sea Basin improved from 2000 to 2019. After the disintegration of the Soviet Union at the end of the $20^{\text {th }}$ century, the central Asian countries experienced contradictions and conflicts in the allocation of water resources. The construction and maintenance of water conservancy facilities in the Aral Sea Basin were affected, and the production layout of the irrigation areas was also changed (Deng and Long, 2011a, b). As a result, the increases in the irrigation area and reservoir capacity in the Aral Sea Basin slowed down, so did the shrinkage rate of the Aral Sea. In order to protect the Aral Sea, central Asian countries have continuously formulated and improved relevant policies on cross-border water resource management in recent years, including the water agreement of the five central Asian countries, the action plan for the environmental and socio-economic improvement in the Aral Sea area (20032010), and the plan for the protection of the North Aral Sea. In recent years, the area of the Aral Sea stabilized and has even slightly expanded; these plans have achieved overall positive results (Yang et al., 2019). This demonstrates the correctness of our conclusions, i.e., the quality of the ecological environment in the Aral Sea Basin improved from 2000 to 2019.

Most of the Aral Sea Basin is sandy land and bare land, with very low vegetation coverage and no obvious change for many years (Kumar, 2002). There is no large-scale change in the surface salinity of the Aral Sea Basin (Kumar, 2002). Therefore, the greenness index and the salinity index were not the decisive indices for the construction of the eco-environmental quality index in the Aral Sea Basin. The desertification of the Aral Sea Basin is severe, and the land degradation area is large (Wu et al., 2009). Moreover, the Aral Sea Basin belongs to a desert ecosystem. The climate in the Aral Sea Basin is dry all year round, and the soil moisture content is low, making it unsuitable for 
planting crops (Khamzina et al., 2008). The second type of soil degradation is caused by the reclamation of cultivated land where the degree of land degradation is low. Therefore, the land degradation index is positively correlated with the eco-environmental quality, making it one of the decisive indicators for establishing the ARSEI. Surface temperature is one of the causes of surface droughts, so the heat index is also a decisive index for establishing the ARSEI.

The main driving force of the temporal variation in the eco-environmental quality in the Aral Sea Basin from 2000 to 2019 was the annual change of the heat index, followed by the annual change of the humidity index. In other words, the different combinations of surface water and heat caused by climate conditions and human activities are the fundamental reasons for the change in the eco-environmental quality in the Aral Sea Basin. There is a general warming trend in the Aral Sea Basin and a general trend of increasing precipitation, resulting in a noticeable transition from warm and dry to warm and humid (Micklin, 2004; Deng and Long, 2011a, b; Touge et al., 2015). Intense human activities (mainly agricultural irrigation and continuous increase of reservoir water storage) are the main factors causing the severe shrinkage of the Aral Sea area and the deterioration of the eco-environment in the Aral Sea Basin (Jiang et al., 2017; Yang et al., 2019). In this study, we compared the different impacts of human activities and climate change, and found that the impact of human activities was higher than that of climate change, which is consistent with the real situation. Consequently, one of the measures needed to improve the eco-environment of the Aral Sea Basin is to make rational use of water resources and to adjust the structure of the agricultural water mainly used for irrigation.

The spatial distribution of the eco-environmental quality in the Aral Sea Basin from 2000 to 2019 is related to the land cover type, and the variance of the spatial distribution is also related to the change in the land cover type. Different land cover types have different surface water and heat contents and different degrees of land degradation. The main reason for the areas with the worst eco-environmental quality in the Aral Sea Basin is that the land cover in the basin is mainly desert and sandy land, with less surface water and more heat resources. From 2000 to 2019, the sharp deterioration of the wetland ecological environment around the Aral Sea was mainly caused by the fact that the area of the Aral Sea has been significantly reduced and the dried lakebeds and the river delta flowing into the Aral Sea have gradually turned into bare land. Therefore, the rational utilization of land resources is one of the measures needed to prevent the further deterioration of the eco-environment in the Aral Sea Basin.

\section{Conclusions}

In this study, by integrating various indicators, we developed the arid remote sensing ecological index (ARSEI) for large-scale arid areas to enhance the applicability of the remote-sensing ecological index (RSEI), to adjust the scope of its application to arid areas, and to expand the spatial scale to the watershed scale. We quantitatively and objectively analyzed the temporal and spatial distribution and the reasons for changes in the eco-environmental quality of the Aral Sea Basin from 2000 to 2019.In the Aral Sea Basin, the heat index and the land degradation index are indispensable indices for building the ARSEI. From 2000 to 2019, in general, the eco-environmental quality in the Aral Sea Basin was graded as worst, but with a trend of initial improvement, then deterioration, and finally further improvement. The basic reason for the temporal variation in the eco-environmental quality in the Aral Sea Basin from 2000 to 2019 was the combined inter-annual change in the surface water and heat. The change in the eco-environmental quality was influenced by human activities more than by natural factors. During the period 2000-2019, except for the areas surrounding the Aral Sea, the ecological environment quality in other areas of the Aral Sea Basin has been generally improved.

The ARSEI developed in this study is mainly based on remote sensing images, which are convenient and timely to obtain. However, the eco-environment in arid areas is also vulnerable to climate disasters, so in the future research, meteorological factors and disaster factors should be added to the index to improve the applicability of the RSEI to arid areas and to better monitor the changes in the eco-environmental quality in arid areas. 


\section{Acknowledgements}

This work was funded by the National Natural Science Foundation of China (U1603242) and the Major Science and Technology Projects in Inner Mongolia, China (ZDZX2018054). The data used in this study were obtained from the NASA (https://ladsweb.modaps.eosdis.nasa.gov/) and the National Tibetan Plateau Data Center (https://data.tpdc.ac.cn/zh-hans/). We also wish to thank the three anonymous reviewers for their helpful comments to improve the manuscript.

\section{References}

Aladin N. 2008. Reclaiming the Aral Sea. Scientific American, 298(4): 64-71.

Allbed A, Kumar L, Aldakheel Y Y J G. 2014. Assessing soil salinity using soil salinity and vegetation indices derived from IKONOS high-spatial resolution imageries: Applications in a date palm dominated region. Geoderma, 230-231: 1-8.

Alves T L B, Azevedo P V D, Santos C A C D, et al. 2015. Influence of climate variability on land degradation (desertification) in the watershed of the upper Paraíba River. Theoretical Applied Climatology, 34(3): 1-11.

Baig M H A, Zhang L, Shuai T, et al. 2014. Derivation of a tasselled cap transformation based on Landsat 8 at-satellite reflectance. Remote Sensing Letters, 5(5): 423-431.

Bennett J. 2003. Opportunities for increasing water productivity of CGIAR crops through plant breeding and molecular biology. In: Kijne J W, Barker R, Molden D. Water Productivity in Agriculture: Limits and Opportunities for Improvement. Colombo: International Water Management Institute Press, 103-126.

Breyfogle N. 2018. Eurasian Environments: Nature and Ecology in Imperial Russian and Soviet History. Pittsburgh University of Pittsburgh Press, 33-34.

Chai L H, Lha D. 2018. A new approach of deriving indicators and comprehensive measure for ecological environmental quality assessment. Ecological Indicators, 85: 716-728.

Dagani R. 1990. Stronger U.S. role in Great Lakes cleanup urged. Chemical \& Engineering News, 68(4): 6 doi: 10.1021/cen-v068n004.p006a.

Deng H J, Chen Y N. 2017. Influences of recent climate change and human activities on water storage variations in Central Asia. Journal of Hydrology, 544: 46-57.

Deng M L, Long A H. 2011a. Evolution of hydrologic and water resources and ecological crisis in the Aral Sea Basin. Journal of Glaciology and Geocryology, 33(6): 1363-1375. (in Chinese)

Deng M L, Long A H. 2011b. Water resources issue among the Central Asian countries around the Aral Sea: conflict and cooperation. Journal of Glaciology and Geocryology, 33(6): 1376-1390. (in Chinese)

Dong Z, Wang Z, Liu D, et al. 2014. Mapping wetland areas using Landsat-derived NDVI and LSWI: a case study of West Songnen Plain, Northeast China. Journal of the Indian Society of Remote Sensing, 42(3): 569-576.

Fan C, Xia B C, Qin J Q. 2013. An integrated assessment model of county level eco-environmental quality based on RS and GIS: A case study of Huidong County, Guangdong Province of South China. Chinese Journal of Ecology, 32(3): 719-725. (in Chinese)

Guo B, Zang W, Han B, et al. 2020a. Dynamic monitoring of desertification in Naiman Banner based on feature space models with typical surface parameters derived from LANDSAT images. Land Degradation \& Development, 31(12): 1573-1592.

Guo B, Zang W, Luo W, et al. 2020b. Detection model of soil salinization information in the Yellow River Delta based on feature space models with typical surface parameters derived from Landsat8 OLI image. Geomatics, Natural Hazards and Risk, 11(1): 288-300.

Hu X S, Xu H Q. 2018. A new remote sensing index for assessing the spatial heterogeneity in urban ecological quality: A case from Fuzhou City, China. Ecological Indicators, 89: 11-21.

Hu X S, Xu H Q. 2019. A new remote sensing index based on the pressure-state-response framework to assess regional ecological change. Environmental Science and Pollution Research, 26(6): 5381-5393.

Jiang C L, Wu L, Liu D, et al. 2019. Dynamic monitoring of eco-environmental quality in arid desert area by remote sensing: Taking the Gurbantunggut Desert China as an example. Journal of Applied Ecology, 30(3): 877-883. (in Chinese)

Jiang L H, Wang W, Yang X, et al. 2010. Classification methods of remote sensing image based on decision tree technologies. In: Li D, Liu Y, Chen Y. Computer and Computing Technologies in Agriculture IV. CCTA 2010. IFIP Advances in Information and Communication Technology, Vol 344. Berlin: Springer, 353-358.

Jiang L L, JIAPAER G L, Bao A, et al. 2017. Vegetation dynamics and responses to climate change and human activities in Central Asia. Science of the Total Environment, 599-600: 967-980.

Kang Y, Cai H J, Song S B. 2012. Application of improved fuzzy matter-element model for assessing eco-environmental quality in 
arid area. Disaster Advances, 5(4): 637-642.

Keith D A, Rodriguez J P, Rodriguez C K M, et al. 2013. Scientific foundations for an IUCN Red List of ecosystems. PLoS ONE, 8(5): e62111, doi: 10.1371/journal.pone.0062111.

Khamzina A, Lamers J P A, Vlek P L G, et al. 2008. Tree establishment under deficit irrigation on degraded agricultural land in the lower Amu Darya River region, Aral Sea Basin. Forest Ecology, 255(1): 168-178.

Khan N M, Rastoskuev V V, Sato Y, et al. 2005. Assessment of hydrosaline land degradation by using a simple approach of remote sensing indicators. Agricultural Water Management, 77(1-3): 96-109.

Kumar R. 2002. Aral Sea: Environmental tragedy in Central Asia. Economic and Political Weekly, 37(37): 14-20.

Langer M, Westermann S, Boike J. 2010. Spatial and temporal variations of summer surface temperatures of wet polygonal tundra in Siberia - implications for MODIS LST based permafrost monitoring. Remote Sensing of Environment, 114(9): 2059-2069.

Li L, Zhang H T. 2008. Assessment model of townlet eco-environmental quality based on BP-artificial neural network. Journal of Applied Ecology, 19(12): 2693-2698. (in Chinese)

Mamat Z, Halik Ü, Keyimu M, et al. 2018. Variation of the floodplain forest ecosystem service value in the lower reaches of Tarim River, China. Land Degradation \& Development, 29(1): 47-57.

McDermid S S, Winter J. 2017. Anthropogenic forcings on the climate of the Aral Sea: A regional modeling perspective. Anthropocene, 20: 48-60.

Micklin P P. 2004. The Aral Sea Crisis. In: Nihoul J C J, Zavialov P O, Micklin P P. Dying and Dead Seas Climatic Versus Anthropic Causes. Berlin: Springer Science \& Business Media Press, 99-123.

Micklin P P. 2007. The Aral Sea disaster. Annual Review of Earth and Planetary Sciences, 35(1): 47-72.

Mladenova I E, Jackson T J, Njoku E, et al. 2014. Remote monitoring of soil moisture using passive microwave-based techniques-Theoretical basis and overview of selected algorithms for AMSR-E. Remote Sensing of Environment, 144: 197213.

Mo K, Chen Q, Chen C, et al. 2019. Spatiotemporal variation of correlation between vegetation cover and precipitation in an arid mountain-oasis river basin in northwest China. Journal of Hydrology, 574: 138-147.

Ning L, Wang J, Fen Q. 2020. The improvement of ecological environment index model RSEI. Arabian Journal of Geosciences, 13(12): 132-137.

Nishikawa H, Yasuda I. 2011. Long-term variability of winter mixed layer depth and temperature along the Kuroshio jet in a high-resolution ocean general circulation model. Journal of Oceanography, 67(4): 503-518.

Nõges P, VandeBund W, Cardoso A C, et al. 2007. Impact of climatic variability on parameters used in typology and ecological quality assessment of surface waters_-implications on the Water Framework Directive. Hydrobiologia, 584(1): 373-379.

Nyimbili P H, Erden T, Karaman H. 2018. Integration of GIS, AHP and TOPSIS for earthquake hazard analysis. Natural Hazards, 92(3): 1523-1546.

Park S K, Marmur A, Russell A G. 2013. Environmental risk assessment: Comparison of receptor and air quality models for source apportionment. Human and Ecological Risk Assessment: An International Journal, 19(5): 1385-1403.

Posthuma L, Suter G W. 2011. Ecological risk assessment of diffuse and local soil contamination using species sensitivity distributions. In: Swartjes F A. Dealing with Contaminated Sites. Dordrecht: Springer, 625-691.

Rastorgueff P A, Bellan S D, Bianchi C N, et al. 2015. An ecosystem-based approach to evaluate the ecological quality of Mediterranean undersea caves. Ecological Indicators, 54: 137-152.

Shan W, Jin X, Ren J, et al. 2019. Ecological environment quality assessment based on remote sensing data for land consolidation. Journal of Cleaner Production, 239: 118126, doi: 10.1016/j.jclepro.2019.118126.

Shobairi S O R, Usoltsev V A, Chasovskikh V. 2018. Dynamic estimation model of vegetation fractional coverage and drivers. International Journal of Advanced and Applied Sciences, 5(3): 60-66.

Smiraglia D, Ceccarelli T, Bajocco S, et al. 2015. Linking trajectories of land change, land degradation processes and ecosystem services. Environmental Research, 147(5): 590-600.

Song Y S, Du C, Yang C, et al. 2012. Ecological environmental quality evaluation of Yellow River Basin. Procedia Engineering, 28: $754-758$.

Sun Q, Zhao K, Zhu L, et al. 2015. A comprehensive evaluation index system for rural environmental quality. Journal of Ecology and Rural Environment, 31(1): 39-43. (in Chinese)

Touge Y, Tanaka K, Nakakita E. 2015. Estimation of climate change impacts on water balance in the Aral Sea basin using terrestrial water circulation model. Journal of Japan Society of Civil Engineers, Series G (Environmental Research), 71(5): I_183-I_188, doi: 10.2208/jscejer.71.I_183.

Wang J, Song P, Wang Z, et al. 2015. A combined model for regional eco-environmental quality evaluation based on particle swarm optimization-radial basis function network. Arabian Journal for Science and Engineering, 41(4): 1483-1493. 
Wang X, Cao L. 2013. Change study of Hongze Lake wetland based on knowledge engineer. Journal of Henan Normal University (Natural Science Edition), 41(5): 148-151. (in Chinese)

Wang Y, Kong J L, Yang L Y, et al. 2019. Remote Sensing Inversion of Soil Moisture in Vegetation-Sparse Arid Areas based on SVR. Journal of Geo-information Science, 21(8): 1275-1283. (in Chinese)

Wang Z, Chang S L, Shi Q D, et al. 2010. Markov process of vegetation cover change in arid area of Northwest China based on FVC index. Journal of Applied Ecology, 21(5): 1129-1136. (in Chinese)

Wei W, Shi P J, Zhou J J, et al. 2013. Assessment of eco-environmental quality of Shiyang River Basin based on GIS and combination weighting method. Advanced Materials Research, 864-867: 1302-1306. (in Chinese)

Wu J L, Ma L, Abuduwaili J. 2009. Lake surface change of the Aral Sea and its environmental effects in the arid region of the Central Asia. Arid Land Geography, 32(3): 418-422. (in Chinese)

Wu T, Sang S, Wang S, et al. 2020. Remote sensing assessment and spatiotemporal variations analysis of ecological carrying capacity in the Aral Sea Basin. Science of the Total Environment, 735: 139562, doi: 10.1016/j.scitotenv.2020.139562.

Xu H Q. 2013. A remote sensing index for assessment of regional ecological changes. China Environmental Science, 33(5): 889897. (in Chinese)

Xu H Q, Wang M Y, Shi T T, et al. 2018. Prediction of ecological effects of potential population and impervious surface increases using a remote sensing based ecological index (RSEI). Ecological Indicators, 93: 730-740.

Xu W Q. 2019. Basic geographic dataset of resources and environment in Central and Western Asia Region. National Tibetan Plateau Data Center. [2020-04-15]. doi: 10.11888/Geogra.tpdc.270491.

Yang X W, Wang N L, Chen A A. 2019. The relationship between human activities, climate change and area variation of the Aral Sea in the arid Central Asia. Journal of Glaciology and Geocryology, 191: 104566, doi: 10.1016/j.catena.2020.104566.

Ying X, Zeng G, Chen G, et al. 2007. Combining AHP with GIS in synthetic evaluation of eco-environment quality - A case study of Hunan Province, China. Ecological Modelling, 209(2-4): 97-109.

Zhang J L, Wang Y J, Ding W Q. 2010. Eco-environmental quality evaluation of Manasi River Basin in recent 30 years. Meteorological and Environmental Research, 1(4): 109-112.

Zhao W C, Qi X Q, Ye X. 2018. Impact of terrain on vegetation coverage estimation method. Journal of Anhui Agricultural Sciences, 46(36): 38-41. (in Chinese)

Zheng M, Zhu M L, Wang Y, et al. 2018. Eco-environment status evaluation and change analysis of Qinghai based on national geographic conditions census data. In: Proceedings of the ISPRS Technical Commission III Midterm Symposium on "Developments, Technologies and Applications in Remote Sensing". Beijing: National Geomatics Center of China, $2453-2457$.

Zheng P, Deng Z D, Wang D Q, et al. 2015. Study on predicting shallow groundwater in semi-arid area based on soil humidity index of TM data: Taking Chaoyang City as a study case. Journal of China Hydrology, 35(5): 23-29. (in Chinese)

Zhou K F, Zhang Q, Chen Q, et al. 2006. Characteristics and trends of eco-environmental changes in arid areas of Central Asia. Scientia Sinica (Terrae), 36(z1): 133-139. (in Chinese)

Zhu H, Wang J L, Cheng F, et al. 2020. Monitoring and evaluation of eco-environmental quality of lake basin regions in Central Yunnan Province, China. Journal of Applied Ecology, 31(4): 1289-1297. (in Chinese) 